\title{
Numerical Study of Thermal and Flow Characteristics of Plate-Fin Heat Sink with Longitudinal Vortex Generator Installed on the Ground
}

\author{
Yen-Tso Chang, ${ }_{1}^{1}$ Han-Ching Lin, ${ }^{1}$ Chi-Jui Huang, ${ }^{1}$ Go-Long Tsai, ${ }^{1}$ and Jinn-Feng Jiang ${ }^{2}$ \\ ${ }^{1}$ Graduate Institute of Mechanical and Electrical Engineering, National Taipei University of Technology, Taipei 10626, Taiwan \\ ${ }^{2}$ Metal Industries Research \& Development Centre, Taipei 10626, Taiwan
}

Correspondence should be addressed to Yen-Tso Chang; changyanzao@gmail.com

Received 28 May 2014; Accepted 11 August 2014; Published 28 August 2014

Academic Editor: Teen-Hang Meen

Copyright (C) 2014 Yen-Tso Chang et al. This is an open access article distributed under the Creative Commons Attribution License, which permits unrestricted use, distribution, and reproduction in any medium, provided the original work is properly cited.

\begin{abstract}
This study applied the commercial software ANSYS CFD (FLUENT), for simulating the transient flow field and investigating the influence of each parameter of longitudinal vortex generators (LVGs) on the thermal flux of a plate-fin heat sink. Vortex generator was set in front of plate-fin heat sink and under the channel, which was in common-flow-down (CFD) and common-flow-up (CFU) conditions, which have the result of vortex generator of delta winglet pair (DWP). In this study the parameters were varied, such as the minimum transverse distance between winglet pair, the attack angle of the vortex generator, fins number, the fin height, and the distance between the vortex generator and plate-fin. The coolant fluid flew into the fin-to-fin channel and pushed the vortex from different geometry toward the bottom. This phenomenon took off the heat from the plate to enhance the heat transfer. The numerical results indicated that the LVGs located close to the plate-fin heat sink are zero with the attack angle being $30^{\circ}$, presenting optimal overall conditions.
\end{abstract}

\section{Introduction}

As electronic devices are getting smaller, the problem of dissipation waste heat becomes more critical. Tiny radiators known as heat sinks are used to convey heat from the electronic components into a cooling air stream. The heat sinks are widely used in many fields such as ground transportation and aerospace industries, refrigeration and air conditioning, and electronics cooling system. The main challenge is to design a heat sink with a fixed size to meet the performance requirement with acceptable heat resistance and least pressure drop ratio. This is an era of high power and high density electronic component equipment, and therefore to meet high power and high density electronics equipment era and enable them to work under either a safety or normal operation temperature and thence how to effectively enhance the thermal performance of electronic components equipment in recent years become a very important research topic.
In electronic systems, a heat sink is a role of passive component which cools a device by dissipating heat into the surrounding air. Heat sinks are used to reduce the temperature of electronic components such as high-power semiconductor devices and photoelectronic devices. A heat sink is designed to increase the surface area in contact with the cooling medium surrounding it, such as air, air velocity, selected material, fin designed, and surface treatment which are the factors to affect the thermal performance of a heat sink. Heat sinks are used to cool computer central processing units or graphics processors. Heat sink attachment methods and thermal interface materials could affect the eventual temperature of the integrated circuit. Theoretical, experimental, and numerical methods could be used to determine a heat sink's thermal performance.

Using fin mode to cool electronic components has been developed over the years. Naik et al. [1] studied the flat ribs of heat transfer characteristics in the rectangular flow channel, which was used for evaluation of the local distribution of 
the convective heat transfer coefficient along the ribs axes within a limited range of rib geometries, indicated that its magnitude and profile were highly influenced by the amount of clearance above the ribs. Lower heat transfer coefficients ensued that a clearance gap was introduced above the rib which varies from constant value to a maximum value at the rib. El-Sayed et al. [2] changed the fin height, fin width, fins' space, number of fins, and the distance of fin tips from the shroud to investigate the performance of plate-fin heat sink; their conclusions were as follows: (1) the pressure drop ratio increased as Reynolds number and fin increased or decreased with increasing interfin space and fin width, (2) increased the clearance between the fin tips and the shroud, and would decrease the mean of Nusselt number, (3) the mean of Nusselt number increases as Reynolds number, fin width and space between fins increases or decreasing fin height. Ducted flow happened in which the air was forced to flow through a channel which fits tightly over the heat sink. It made sure that all of the air went through the channels formed by the fins of the heat sink. When the air flow is not ducted, a certain percentage of air flow would bypass the heat sink. Flow bypass was found to increase fin density and clearance, while remaining relatively insensitive to inlet duct velocity [3]. El-Sayed et al. [4] studied the heat transfer and fluid flow of a plate-fin heat sink for the cases of parallel flow, impinging flow, and reversed impinging flow; a parallel flow would yield the greatest rate of heat transfer and the least pressure drop ratio. For all cases, the local Nusselt number increased from the base to the tip in the vertical direction; its value increased with increasing Reynolds number and with increasing distance from the leading edge of the fin in the stream-wise direction. The fin efficiency for parallel flow was greater than that for the other two cases in the core region. Elshafei [5] assessed the thermal fluid performance of a plate-fin heat sink under cross-flow conditions, both experimentally and theoretically, through parameters for the mainstream velocity, fin density, and clearance between tip and shroud; their effects on the bypass flow, the pressure drop ratio, and the thermal performance were discussed. The mean heat-transfer coefficient decreased with increasing clearance between tip and shroud, but the effect of this clearance on the mean heat-transfer coefficient decreased as Reynolds number increased. In order to enhance the heat transfer of fin in rectangular flow channel, Li et al. [6] applied a CFD numerical method; the influence of fin width, fin height, number of fins, and Reynolds number was assessed without and with a shield. The research discovered that the place of back plate and front plate could reduce bypass effect and forced the fluid to enter plate-fin to enhance the heat conduction, but the pressure drop ratio would also increase. Wirtz et al. [7] studied the effects of flow bypass on the performance of ducted longitudinal heat sinks. It is indicated that the value of flow bypass was found up to $60 \%$ and resulted in a reduction of the overall heat transfer rate. Quantifying the effect of coolant bypass on the thermal performance of the heat sink element was also reported. Tsai et al. [8] investigated the effect of the angle of inclination of a plate heat shield on the thermal and hydraulic performance of a plate-fin heat sink. The research discovered that the sloping baffle was unable to reduce the thermal resistance but could actually reduce the pressure drop effectively. Vortices were determined by the specific base flow and vortex generator. Developing and fully developed channel flows have been considered base flow. Different wing types have been considered as vortex generators. They could easily be incorporated into heat transfer surfaces by embossing, stamping, or attaching them as fins to primary heat transfer surfaces. Wing-type vortex generators allowed us to control the type and enlarge the generated vortices by the form, area, and angle of attack of the wings. Vortices increased the rate of kinetic energy flux and dramatically changed transition Reynolds number, temperature profile, and their gradients at the wall. They enhanced friction and heat transfer [9].

A vortex generator was an aerodynamic surface, comprising a small vane or bump that created a vortex. To study the effect of vortex generator, many scholars conducted the research using the experiment or the numerical simulation ways. Sohankar [10] set a channel with two angled ribs as a vee-shaped vortex generator to augment heat transfer by the numerical simulation. Discusses the Reynolds number and the rib included angle regarding the flow field and heat influence of the transfer performance, its conclusion indicated that increased vortex generator was possible to promote the heat transfer effect in the flow channel but would also create pressure losses. Sohankar and Davidson [11] used the numerical simulation way, laying aside incline's massive vortex generator in the rectangular flow channel, and discussed the three-dimensional unsteady flow and the heat transfer phenomenon. This research changed vortex generator thickness, place angle, and upstream length and hereafter found that Reynolds number was smaller than 1000; flow started and appeared stable. But the Reynolds number is bigger than 1000; then flows started and appeared stable. Moreover, the Nusselt number and the friction factor increased along with the angle and the Reynolds number, the increment of friction factor came to fast than the Nusselt number did. To increase vortex generator the thickness, would let leading edges of vortex generator result in the bigger Nusselt number and would produce the strong turbulent flow in the downstream and then had the higher Nusselt number and would increase along with the Reynolds number fill-out. Wu and Tao [12] presented the influences of main parameters of LVGs on the heat transfer enhancement and flow resistance in a rectangular channel. These parameters included the location of LVGs in the channel, geometric sizes, and shape of LVGs. Numerical results showed that the overall Nusselt number of channels would decrease with the LVGs location away from the inlet of the channel and would decrease as the space of the LVG pair is decreasing. Henze et al. [13] experimentally investigated the velocity field and wall heat transfer distributions for internal flows in the presence of longitudinal vortices. And Tian et al. $[14,15]$ studied the effects of two different shaped LVGs, rectangular winglet pair (RWP) and delta winglet pair (DWP) with two different configurations, common-flow-down and common-flow-up. The rectangular wing as well as the delta, respectively, by CFU and the CFD structure disposition, could accelerate the fluid mix and strengthen the heat transfer. 


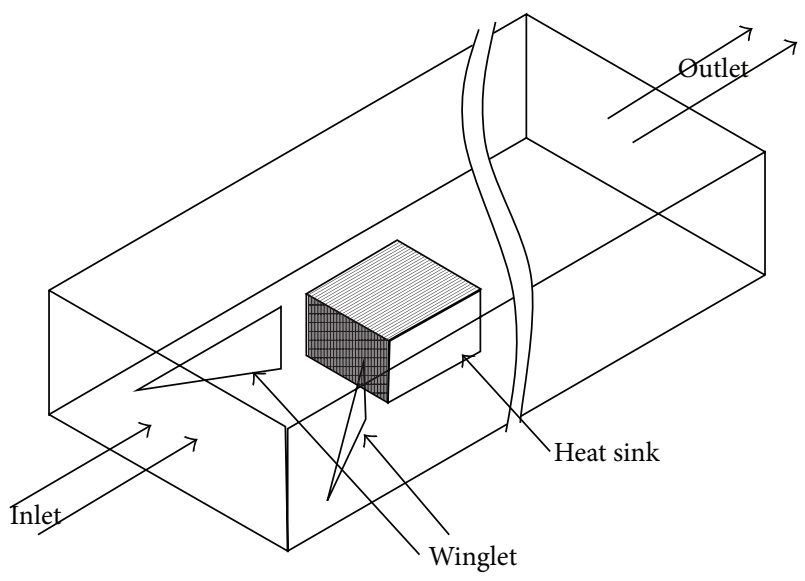

FIGURE 1: Schematic geometric model.

In this study, we changed the flow structure to enhance heat transfer effect by utilizing the delta winglet pair longitudinal vortex generator which was set in front of the radiator to mix the air surrounding radiator and the fins. Most of the current scholars used to change the fin shape to improve the performance of plate-fin heat sink and vortex generator for the multi-fin-tube heat exchanger. Only few studies installed vortex generator for plate-type heat sink to enhance heat transfer effect. This study was intended to develop a design with low thermal resistance and to provide a new design direction for the present plate-fin heat sink cooling module design.

\section{Analysis}

The geometry of the theoretical model and the boundary conditions was illustrated and shown in Figure 1. The dimensions of the theoretical model were $3 \mathrm{~m} \times 0.09 \mathrm{~m} \times 0.2 \mathrm{~m}$ $(X \times Y \times Z)$. In order to save the computation duration, applied symmetric geometry, the real calculation field of volume was $3 \mathrm{~m} \times 0.09 \mathrm{~m} \times 0.1 \mathrm{~m}$. Figure 2 was the schematic diagram and showed the parameters of the computational fluid dynamics model. The thermal and flow fields were calculated numerically with FLUENT 6.3, according to the following assumptions.

(1) The system was a steady state.

(2) The flow was incompressible and turbulent.

(3) The fluid and the solid properties were constant.

(4) The effects of gravity and thermal radiation are neglected.

(5) The effect of turbulence on the flow field was included by application of the RNG $\kappa-\varepsilon$ turbulence model [16].

The Reynolds number was defined as

$$
\operatorname{Re}=\frac{\rho U_{\mathrm{o}} D}{\mu} .
$$

$D$ was hydraulic diameter which was calculated by 4 times of duct cross-sectional area and divided by the wetted perimeter; the value is $0.124 \mathrm{~m}$. Besides heater area
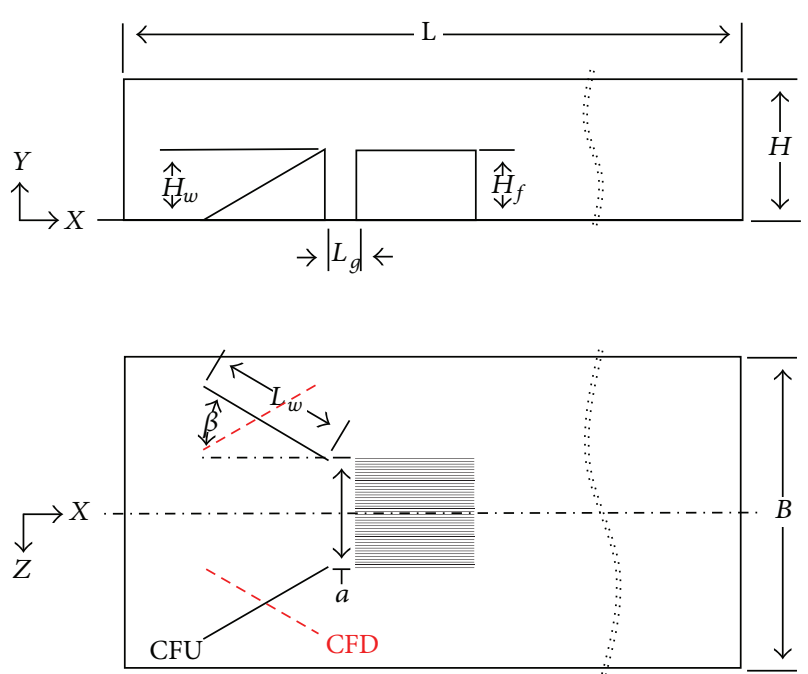

FiguRE 2: Parameter diagram.

$(0.031 \mathrm{~m} \times 0.031 \mathrm{~m})$, the base of heat sink was heat insulation, and the thermal conductivity of heat sink was $168 \mathrm{~W} / \mathrm{mk}$.

Hybrid meshing was used in the study; the grid construction was adopted tetrahedron mesh and hexahedral mesh complex ways. Heat sink area and rectangular channel had hexahedral mesh construction, and vortex generators and surrounding area was used tetrahedron mesh construction. The pressure term was treated with a standard approach, but the pressure-velocity coupling solved with the SIMPLE algorithm [16], which was used to solve fluid flow and heat transfer problems. The convergence criterion to terminate the computation was defined as $10^{-8}$ for the scaled residual of the energy equation or $10^{-5}$ for the scaled residual of other equations.

The thermal resistance $R_{\mathrm{th}}$ was defined as follows:

$$
R_{\mathrm{th}}=\frac{T_{\mathrm{ave}}-T_{\mathrm{in}}}{\mathrm{Q}},
$$

where $T_{\text {ave }}$ was the surface temperature of heat sink base, $Q$ was total heat rate into the heat sink, and $T_{\text {in }}$ stands for the inlet temperature which was $293^{\circ} \mathrm{K}$. Pressure drop $(\Delta p)$ was defined as

$$
\Delta p=p_{\text {in }}-p_{\text {out }},
$$

where $p_{\text {in }}$ was pressure of inlet and $p_{\text {out }}$ was pressure of outlet.

The overall performance was defined as $\left(R_{\text {th,ref }}\right.$ $\left./ R_{\mathrm{th}}\right) /\left(\Delta P / \Delta P_{\text {,ref }}\right)$. To verify the accuracy of physical model and numerical method, using grid independence correction method simulated LVGs on the front tip of heat $\operatorname{sink}\left(L_{g}=0\right.$, $a=3 H$ ), attack angle is 15 degree in CFU, with $0.008 \mathrm{~m}$ thickness and $0.045 \mathrm{~m}$ height of plate-fin heat sink in 10,000 Reynolds number.

\section{Results and Discussion}

The applied grid system was certified under conditions of a heat sink with $W_{f}=0.002 \mathrm{~m}$ and $H_{f}=0.045 \mathrm{~m}$ and a 


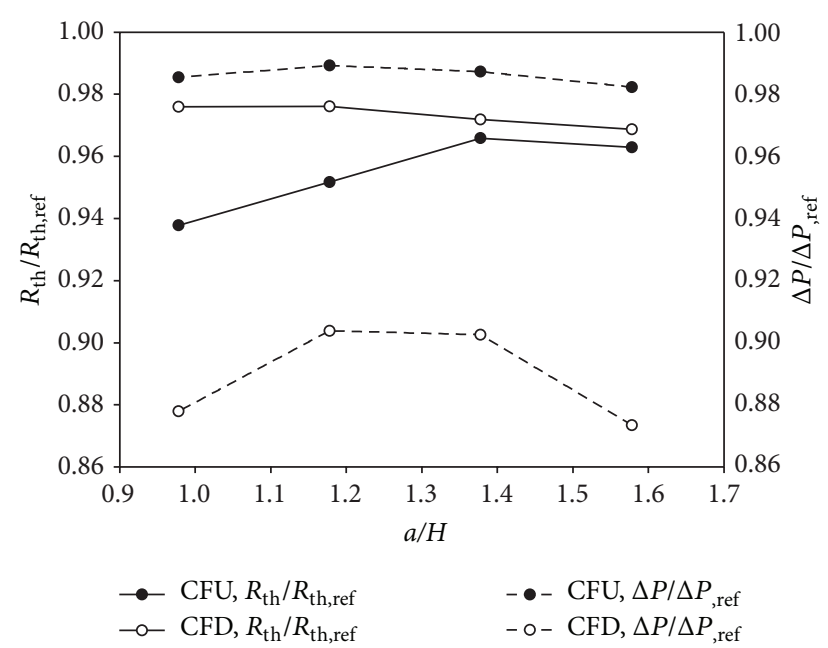

FIGURE 3: The influence of flow configurations on thermal resistance ratio and pressure drop ratio $\left(W_{f}=0.002 \mathrm{~m}, H_{f}=0.045 \mathrm{~m}, H_{w}=\right.$ $0.045 \mathrm{~m}, L_{g}=0, \beta=15^{\circ}$, and $\left.\operatorname{Re}=10,000\right)$.

vortex generator of angle $\beta=15^{\circ}$ at $\operatorname{Re}=10,000$ and was meshed with four different grid numbers of 717,000, 855,000, 966,000 , and 1,181,000. The computational results of the mean surface temperature of the heat sink varied from $0.03893 \%$ to $0.03337 \%$ deviation. Deducing the thermal resistance, the number of grids increased from 855,000 to $1,181,000$. The computational result of the mean surface temperature of the heat sink was varied within $0.00556 \%$, with a deduced $0.006 \%$ deviation in thermal resistance, as the number of grids increased from 966,000 to $1,181,000$. In order to save computing time without penalizing the accuracy, the model with 966,000 grids was selected for this research.

3.1. Comparison of CFU and CFD. Figure 3 showed the influence of flow configurations on thermal resistance ratio and pressure drop ratio at $\beta=15^{\circ}$. It was found that the heat transfer was more intensive when the transverse distance between the winglet pair became less. The temperature contours on the symmetric plane along the main flow direction for the different configurations at $\beta=15^{\circ}$ were shown in Figure 4 . It could be seen that the longitudinal vortices had significant influence on the temperature distribution of the symmetry and the change of the thermal boundary layer thickness near the fins. For the CFU configuration, the flow brought the fluid closer to the heat sink and decreased the temperature of the heat sink than those in CFD configuration did. The thermal boundary layer was thinner in CFU than in CFD. The flow took the cool fluid from the midregion to the hot heat sink, and therefore CFU had higher temperature gradient near the heat sink and better heat transfer than those in CFD. We applied CFU framework to study the ideal location for erecting vortex generator in the flow channel in this study.

3.2. Minimum Transverse Distance between Winglet Pair. The variation of the thermal resistance ratio and pressure drop ratio under minimum transverse distance between winglet pair was shown in Figure 5. Decreasing the transverse space between the winglet pair (decreasing the value of $a$ ) caused a great increase in upstream pressure of the plate-fin heat sink and also caused many impacts on the thermal resistance. The rear of the LVGs touched on plate-fin heat sink and small minimum transverse distance between winglet pair could provide the best overall performance among all the conditions. The LVGs enhanced the heat transfer of the channel. The top view showed the strong three-dimensionality of the flow field. The decreasing value of minimum transverse distance between winglet pair showed that the increase in the coolant fluid was forced to impact the leading edges of the plate-fin heat sink. As a result, the shorter distance between winglet pair caused high speed fluid flow into the fin-to-fin channel to enhance thermal performance. However, we could find that the backflow of the LVG had directly effects on the flow behind the heat sink, and the case with $a=0.777 \mathrm{H}$ had the largest effect among all the cases. This was because the upper air drove the middle fluid to flow and that could produce stronger up-wash vortex. If we increased " $a$ ", the efficiency of thermal resistance will rise. This was because moving vortex generator near the heat sink would cause the highest pressure drop ratio and decrease flow performance and would not effectively influence the backflow of the platefin heat sink. Decreasing distance between winglet pair would enhance the heat transfer of the fin channel and increase the pressure drop ratio, but the increase in the heat transfer is larger than the amount decreased in the pressure drop ratio. The transfer of heat by the heat sink became worse when the minimum transverse distance between winglet pair of the vortex generators was too small and that would affect the entry of the flow into the heat sink [17].

3.3. The Distance between the Vortex Generator and Heat Sink. Figure 6 showed the effect of the distance between the vortex generator and heat sink on the thermal resistance ratio and pressure drop ratio of heat sink. Optimal overall performance occurred when the distance between the vortex generator and heat sink was equal to zero and that could be seen in Figure 6. When the vortex generator was close to the plate-fin heat sink, it could cause small thermal resistance. That is, as the trailing edge of vortex generator touched the leading edge of the platefin heat sink $\left(L_{g}=0\right)$, it produced strong vortex. But, as $L_{g}=2 \mathrm{H}$ changed to $L_{g}=3 \mathrm{H}$, it reduced thermal resistance and the slope was gradually smooth. An operative range of the distance between the vortex generator and heat sink was $0 \leqq$ $L_{g} \leqq 3 H$. Meanwhile, Figure 6 displayed smallest pressure drop ratio at $L_{g}=0.5 \mathrm{H}$, which enhanced fluid performance, but the other position as $L_{g}=0$ and $L_{g}=3 H$ would cause much drag with increased pressure drop ratio. Contours of vorticity magnitude in various cross-sections along the main flow direction for the different distance between the vortex generator and heat sink for $\operatorname{Re}=10,000$ were shown in Figures 7-9 (without displaying plate-fin heat sink, $W_{f}=$ $0.002 \mathrm{~m}, H_{f}=0.045 \mathrm{~m}, H_{w}=0.045 \mathrm{~m}, a=0.777 \mathrm{H}$, $\beta=15^{\circ}$, and $\left.\operatorname{Re}=10,000\right)$. It could be found that vorticity intensity behind the heat sink gradually decreases 


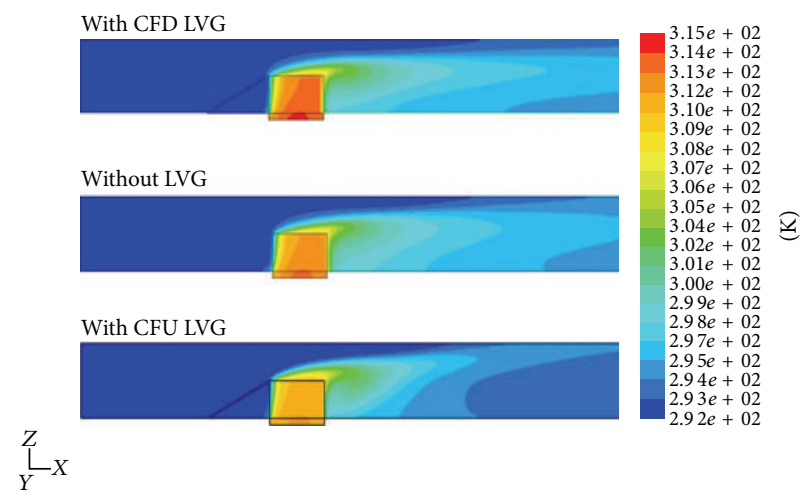

FIGURE 4: Temperature contours on the symmetric plane along the main flow direction in the different configurations at $\beta=15^{\circ}$.

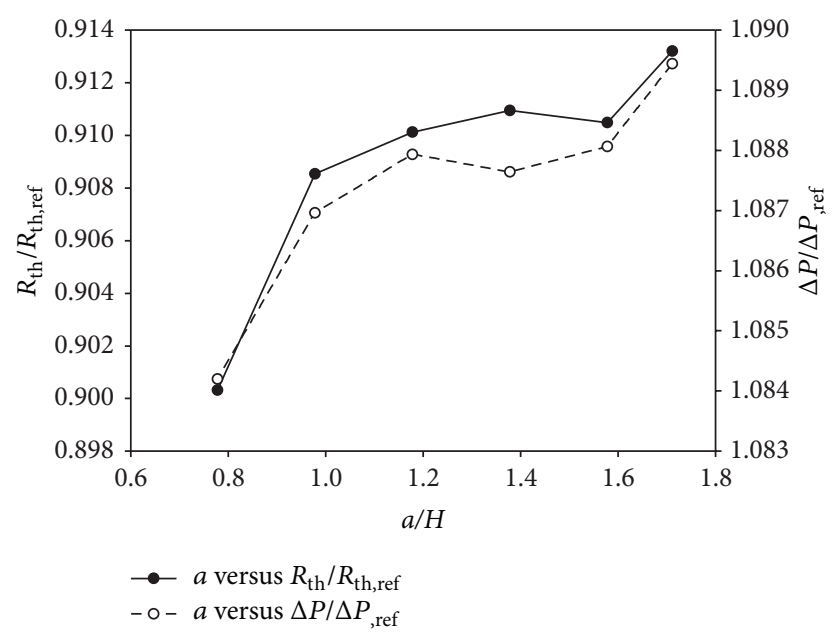

FIGURE 5: Thermal resistance and pressure drop ratio distributions under minimum transverse distance between the winglet pair $\left(W_{f}=\right.$ $0.002 \mathrm{~m}, H_{f}=0.045 \mathrm{~m}, H_{w}=0.045 \mathrm{~m}, L_{g}=0, \beta=15^{\circ}$, and $\operatorname{Re}=$ $10,000)$.

and thermal resistance evidently increased with the increase in the distance between the vortex generator and heat sink. And, therefore, from Figure $6, L_{g}=2 \mathrm{H}$ changed to $L_{g}=3 \mathrm{H}$ and caused gradually smooth thermal resistance line, because flow rate of through the plate fin at $L_{g}=2 \mathrm{H}$ was quicker than at $L_{g}=3 H$. It is interesting to note that in the position between $L_{g}=2 \mathrm{H}$ and $L_{g}=3 \mathrm{H}$, compared with Figures 8 and 9 , the one with higher $L_{g}$ has higher vorticity intensity of channel and better heat transfer performance than the one with lower $L_{g}$.

Figure 10 showed the comparison of the path-line at vortex generator and heat sink under the conditions $\beta=15^{\circ}$ and $a=0.777 \mathrm{H}$ with $\mathrm{Re}=10,000$ between the cases of $L_{g}=0, L_{g}=0.5 H$, and $L_{g}=3 H$ from the top view. The top view showed the strong three-dimensionality of the flow field. With vortex generator close to heat sink $\left(L_{g}=0\right)$, a decreased $L_{g}$ increases the pressure drop ratio of the channel because large amount of the compressed fluid stuck on the leading edge of the plate-fin heat sink and had great impact on the thermal resistance. The trends also could

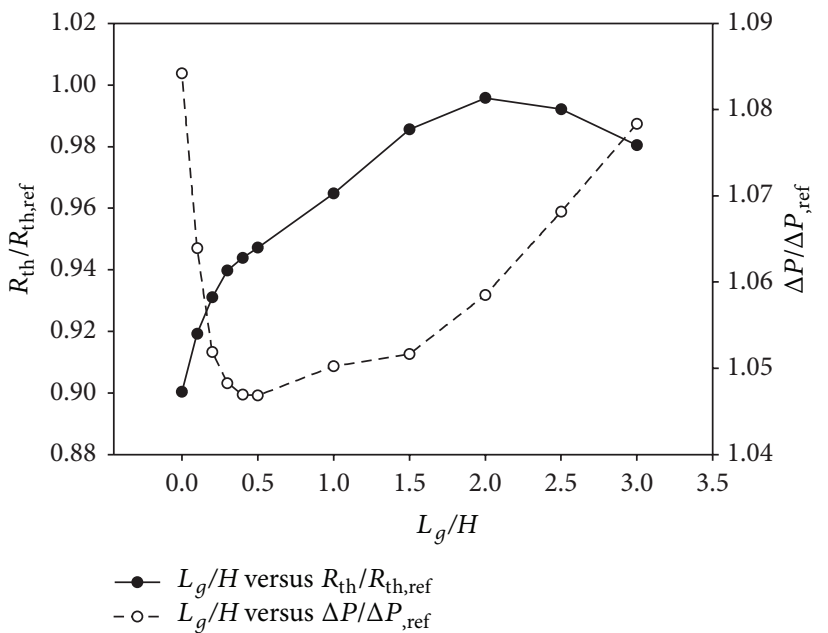

FIGURE 6: The effects of the distance between the vortex generator and heat sink on the thermal resistance ratio and pressure drop ratio of heat sink $\left(W_{f}=0.002 \mathrm{~m}, H_{f}=0.045 \mathrm{~m}, H_{w}=0.045 \mathrm{~m}, a=\right.$ $0.777 H, \beta=15^{\circ}$, and $\left.\operatorname{Re}=10,000\right)$.

be seen in Figure 6. There were great drops in the curve of the thermal resistance ratio around the two extremes, $L_{g}=0$ and $L_{g}=3 \mathrm{H}$, but the case with $L_{g}=0.5 \mathrm{H}$ had lower thermal resistance ratio than the others. When the longitudinal vortices develop downstream at $L_{g}=3 \mathrm{H}$, the vortex intensity was gradually weakened. On the other hand, the longitudinal vortices strongly took away the heat of trailing edge of the heat sink at $L_{g}=0.5 \mathrm{H}$. Based on this finding, we used the $L_{g}=0$ as the baseline setting for the following study.

3.4. The Attack Angle of the Vortex Generator. Figure 11 illustrated the numerical and experimental results on thermal resistance ratio and pressure drop ratio of heat sink, with $a=0.777 \mathrm{H}, L_{g}=0$, and various attack angles of vortex generator. At elevated attack angle of vortex generator $\beta=$ $15^{\circ}$, thermal resistance across the plate-fin heat sink became significant; then attack angle of vortex generator $\beta=45^{\circ}$ had lowest thermal resistance. Increasing the attack angle of 


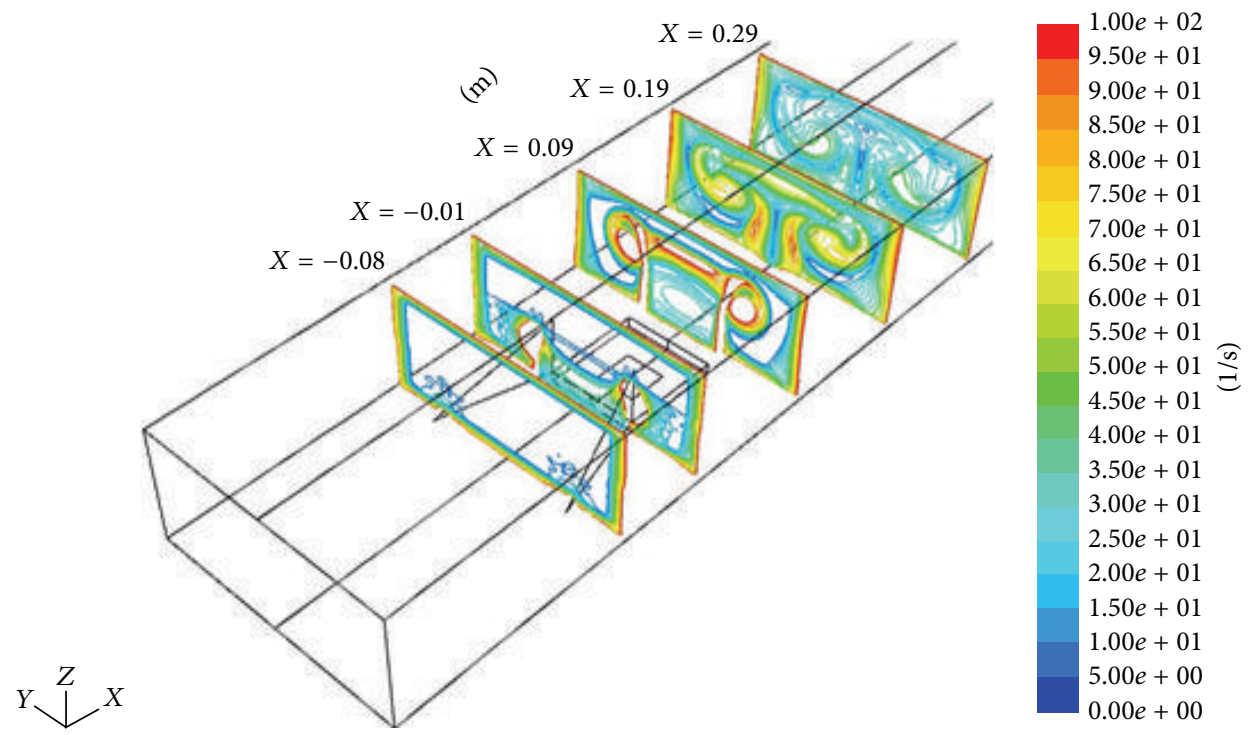

FIGURE 7: Contours of vortices magnitude in various cross-sections along the main flow direction $\left(W_{f}=0.002 \mathrm{~m}, H_{f}=0.045 \mathrm{~m}, H_{w}=\right.$ $0.045 \mathrm{~m}, a=0.777 \mathrm{H}, L_{g}=0, \beta=15^{\circ}$, and $\operatorname{Re}=10,000$, without displaying plate-fin heat sink).

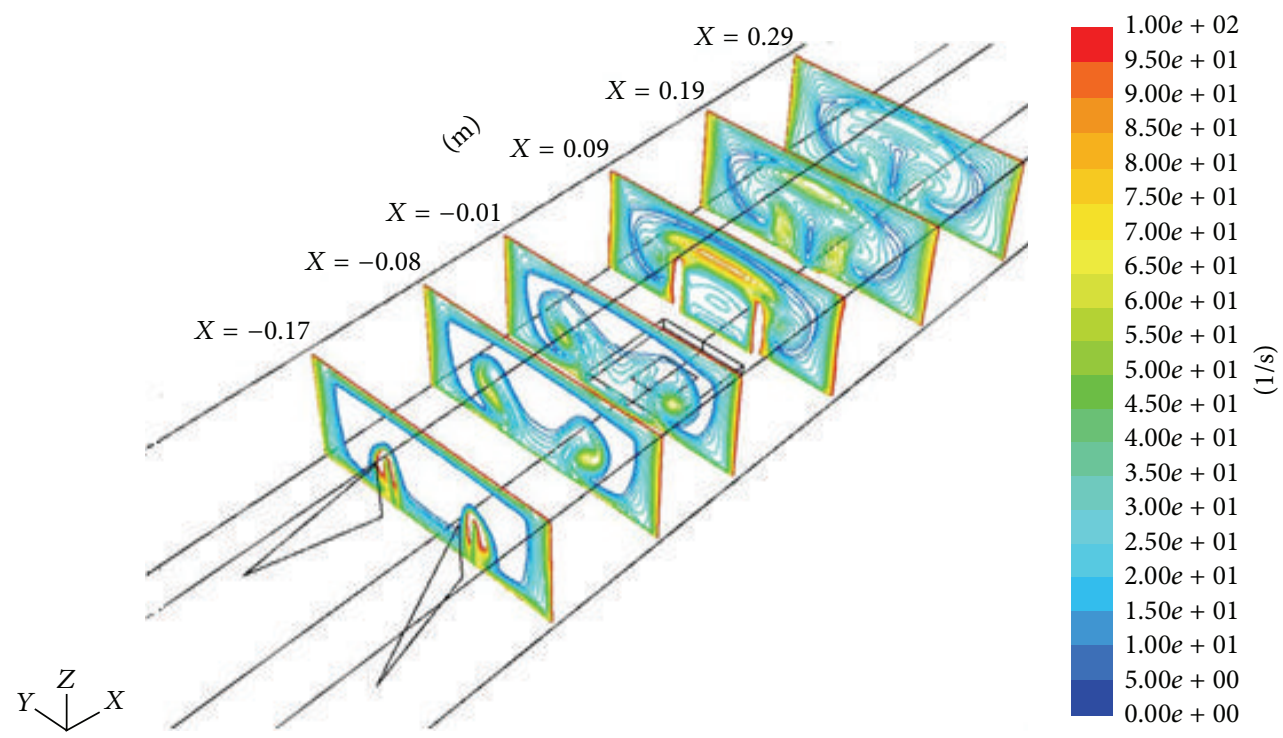

FIGURE 8: Contours of vortices magnitude in various cross-sections along the main flow direction $\left(W_{f}=0.002 \mathrm{~m}, H_{f}=0.045 \mathrm{~m}, H_{w}=\right.$ $0.045 \mathrm{~m}, a=0.777 \mathrm{H}, L_{g}=2 H, \beta=15^{\circ}$, and $\mathrm{Re}=10,000$, without displaying plate-fin heat sink).

vortex generator would greatly increase $X$-direction backflow velocity gradient of the trailing edge of heat sink.

The effect of attack angle of vortex generator on the overall performance of plate-fin heat sink in comparison to numerical and experimental results was shown in Figure 12. Increasing the attack angle would cause the increase in the blockage of the channel and enhances overall performance. Part of the fluid entered through the fin-to-fin channel to perform heat transfer, but the other accelerated from the side of the heat sink with strong vortices. The importance of the attack angle of vortex generator on pressure drop ratio was great and should be considered, especially at small fin height and more fins numbers. When attack angle $\beta=15^{\circ}$, inlet zone had the smallest pressure among the three cases. Similarly, increasing attack angle would also increase inlet zone pressure and enhanced pressure drop ratio of channel. These results were consistent with previous discussion and met an optimal design rule.

Figures 11 and 12 showed the trend of the pressure drop ratio and overall performance of heat sink (triangle up) which were in a good agreement with the experimental data [18]. But thermal resistance ratio was quite different from each other, because cooling area of heat sink was larger on experimental model. 


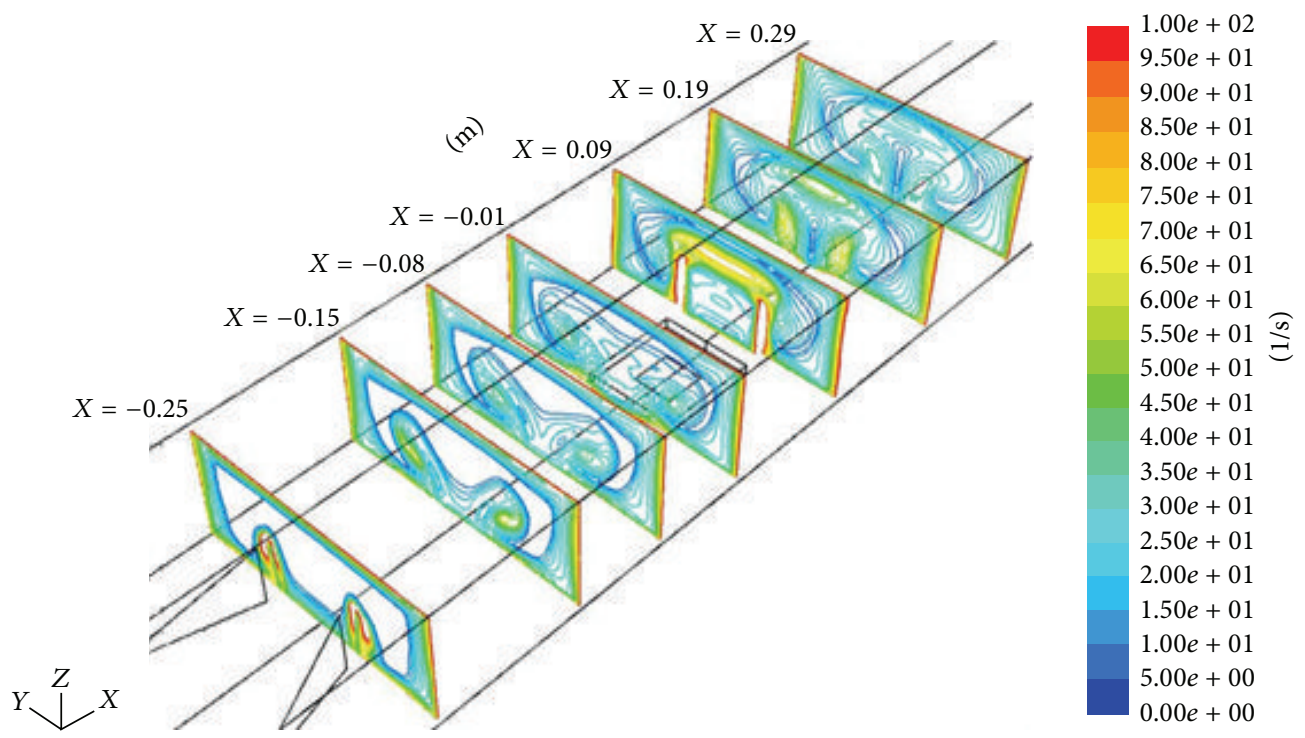

FIGURE 9: Contours of vortices magnitude in various cross-sections along the main flow direction $\left(W_{f}=0.002 \mathrm{~m}, H_{f}=0.045 \mathrm{~m}, H_{w}=\right.$ $0.045 \mathrm{~m}, a=0.777 \mathrm{H}, L_{g}=3 H, \beta=15^{\circ}$, and $\mathrm{Re}=10,000$, without displaying plate-fin heat sink).

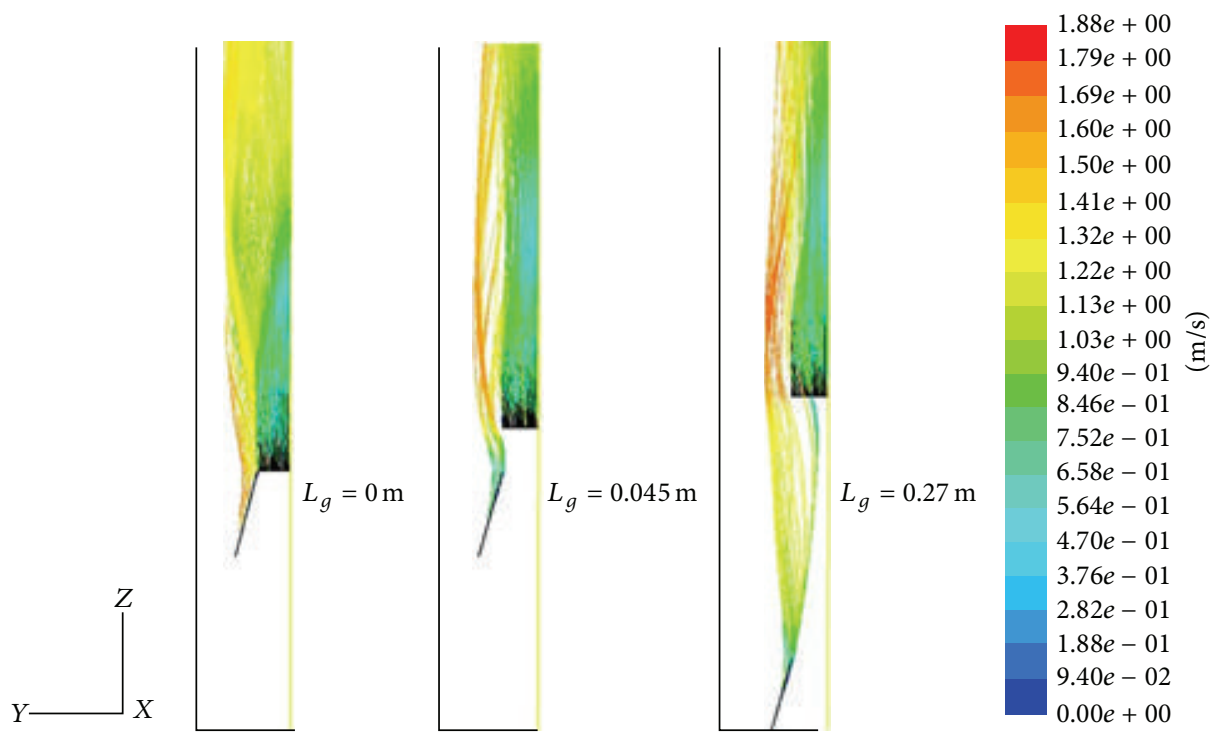

FIGURE 10: Flow structures around LVG and heat sink at the distance between the vortex generator and heat sink; $L_{g}=0, L_{g}=0.5 H$, and $L_{g}=3 H\left(W_{f}=0.002 \mathrm{~m}, H_{f}=0.045 \mathrm{~m}, H_{w}=0.045 \mathrm{~m}, a=0.777 H, \beta=15^{\circ}\right.$, and $\left.\operatorname{Re}=10,000\right)$.

3.5. Fins Number and Fin Height. Figure 13 showed thermal resistance ratio and pressure drop ratio with the distance between vortex generator and heat sink when fins number equaled ten and twenty. The pressure drop ratio caused by the fins number would increase with increasing fin height and attachment of vortex generator and that would reinforce this tendency. When fins number and fin height were increased, the blockage effect would enforce more fluid concentrated on the plate-fin sink. And, therefore, the flow on side of heat sink region would be more obvious than that on the terminal region. Most of the flow visualization around the heat sink would illustrate this flow behavior. But, in the case of 20 fins with more total cooling area of plate-fin heat sink, it was noticed that (see Figure 6) most of the flow escapes from interfin region to tip fins area and quickly enters from the ceiling region to terminate fins direction. This produced thermal boundary layer would be thin on the terminal region. Consequently, the value of thermal resistance was lower than fins number $n=10$ case. Generally, increasing number of fins could enhance the thermal performance, but this influence was insignificant for the height of a high fin.

\section{Conclusion}

The influences of main parameters of longitudinal vortex generator and plate-fin heat sink on heat transfer enhancement 


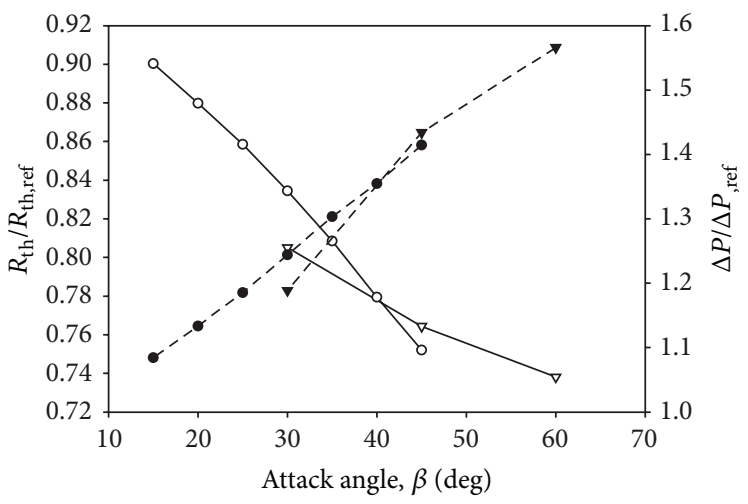

$$
\begin{aligned}
& \rightarrow-n=20, \text { experimental (Chen, 2012) } \\
& -\nabla-n=20, \text { experimental (Chen, 2012) } \\
& \multimap n=10, \text { numerical } \\
& -\bullet-n=10, \text { numerical }
\end{aligned}
$$

FIGURE 11: Thermal resistance ratio and pressure drop ratio distributions for attack angle of vortex generator between the computed results and experimental data $\left(W_{f}=0.002 \mathrm{~m}, H_{f}=0.045 \mathrm{~m}, H_{w}=0.045 \mathrm{~m}, a=0.777 H, L_{g}=0\right.$, and $\left.\operatorname{Re}=10,000\right)$.

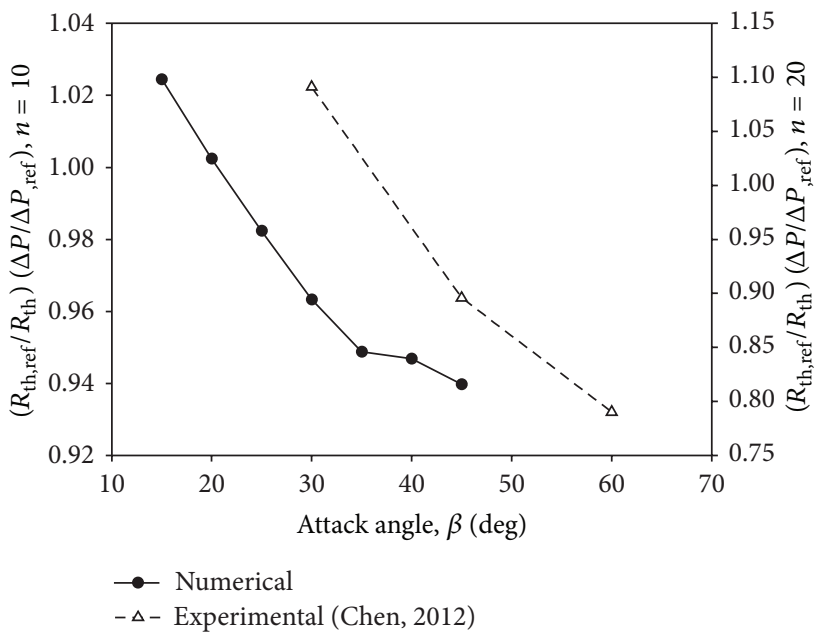

FIGURE 12: Variation of overall performance with the attack angle between the computed results and experimental data $\left(W_{f}=0.002 \mathrm{~m}\right.$, $H_{f}=0.045 \mathrm{~m}, H_{w}=0.045 \mathrm{~m}, a=0.777 H, L_{g}=0$, and $\left.\mathrm{Re}=10,000\right)$.
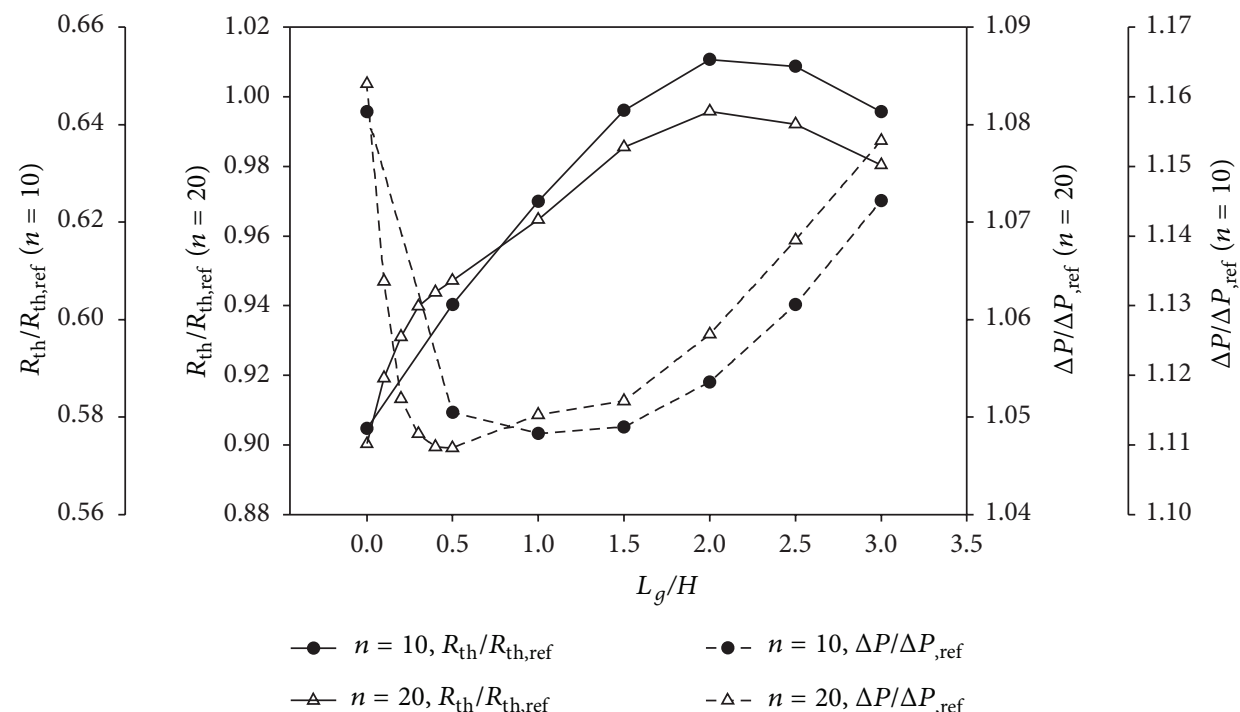

FIGURE 13: The effects of the distance between the vortex generator and heat sink for fins numbers $n=10,20$ and attack angle $\beta=30^{\circ}$ on the thermal resistance ratio and pressure drop ratio of heat sink $\left(W_{f}=0.002 \mathrm{~m}, H_{f}=0.045 \mathrm{~m}, H_{w}=0.045 \mathrm{~m}, a=0.777 H\right.$, and $\left.\operatorname{Re}=10,000\right)$. 
and flow resistance were numerically computed and analyzed in the present paper. So the following could be concluded.

(1) The LVG would increase the pressure drop ratio of the fluid flow in the channel. The thermal resistance of heat sink with LVG was lower than that without LVG, and the thermal resistance of heat sink with common-flow-down configuration was larger than that of common-flow-up configuration.

(2) Using longitudinal vortex generator could effectively change flow configuration of channel; it also agitated backflow of plate-fin heat sink and enhanced heat transfer performance with accelerating the cooling process by decreasing the minimum transverse distance between winglet pair and distance between vortex generator and heat sink.

(3) Regarding a balance between thermal resistance and flow performance, minimum transverse distance between winglet pair $a=0.777 \mathrm{H}$ and distance between vortex generator and heat sink $L_{g}=0$ with attack angle $\beta=30^{\circ}$ were an optimal design.

Increasing the fins number would enhance the performance of the heat sink. Oppositely, as the number of fins and the height of the fin are increased, the heat dissipation performance would decrease significantly. Increasing the fin height and fins number could decrease flow area of channel. In this study, installing vortex generator would decrease thermal resistance as fins number $n=20$ is evidently better than the fins number $n=10$.

\section{Conflict of Interests}

The authors declare that there is no conflict of interests regarding the publication of this paper.

\section{References}

[1] S. Naik, S. D. Probert, and I. G. Bryden, "Heat transfer characteristics of shrouded longitudinal ribs in turbulent forced convection," International Journal of Heat and Fluid Flow, vol. 20, no. 4, pp. 374-384, 1999.

[2] S. El-Sayed, S. M. Mohamed, A. M. Abdel-latif, and A.-H. E. Abouda, "Investigation of turbulent heat transfer and fluid flow in longitudinal rectangular-fin arrays of different geometries and shrouded fin array," Experimental Thermal and Fluid Science, vol. 26, no. 8, pp. 879-900, 2002.

[3] S. Prstic, M. Iyengar, and A. Bar-Cohen, "Bypass effect in high performance heat sinks," in Proceedings of the International Thermal Science Seminar, pp. 11-14, Bled, Slovenia, June 2000.

[4] S. A. El-Sayed, S. M. Mohamed, A. M. Abdel-Latif, and A. E. Abouda, "Experimental study of heat transfer and fluid flow in longitudinal rectangular-fin array located in different orientations in fluid flow," Experimental Thermal and Fluid Science, vol. 29, no. 8, pp. 113-128, 2004.

[5] E. A. M. Elshafei, "Effect of flow bypass on the performance of a shrouded longitudinal fin array," Applied Thermal Engineering, vol. 27, no. 13, pp. 2233-2242, 2007.
[6] H.-Y. Li, G.-L. Tsai, M.-H. Chiang, and J.-Y. Lin, "Effect of a shield on the hydraulic and thermal performance of a platefin heat sink," International Communications in Heat and Mass Transfer, vol. 36, no. 3, pp. 233-240, 2009.

[7] R. A. Wirtz, W. Chen, and R. Zhou, "Effects of flow bypass on the performance of longitudinal fin heat sinks," Journal of Electronic Packaging, vol. 116, no. 3, pp. 206-211, 1994.

[8] G.-L. Tsai, H.-Y. Li, and C.-C. Lin, "Effect of the angle of inclination of a plate shield on the thermal and hydraulic performance of a plate-fin heat sink," International Communications in Heat and Mass Transfer, vol. 37, no. 4, pp. 364-371, 2010.

[9] M. Fiebig, "Embedded vortices in internal flow: heat transfer and pressure loss enhancement," International Journal of Heat and Fluid Flow, vol. 16, no. 5, pp. 376-388, 1995.

[10] A. Sohankar, "Heat transfer augmentation in a rectangular channel with a vee-shaped vortex generator," International Journal of Heat and Fluid Flow, vol. 28, no. 2, pp. 306-317, 2007.

[11] A. Sohankar and L. Davidson, "Effect of inclined vortex generators on heat transfer enhancement in a three-dimensional channel," Numerical Heat Transfer A: Applications, vol. 39, no. 5, pp. 433-448, 2001.

[12] J. M. Wu and W. Q. Tao, "Numerical study on laminar convection heat transfer in a channel with longitudinal vortex generator. Part B: parametric study of major influence factors," International Journal of Heat and Mass Transfer, vol. 51, no. 1314, pp. 3683-3692, 2008.

[13] M. Henze, J. von Wolfersdorf, B. Weigand, C. F. Dietz, and S. O. Neumann, "Flow and heat transfer characteristics behind vortex generators-a benchmark dataset," International Journal of Heat and Fluid Flow, vol. 32, no. 1, pp. 318-328, 2011.

[14] L.-T. Tian, Y.-L. He, Y.-G. Lei, and W.-Q. Tao, "Numerical study of fluid flow and heat transfer in a flat-plate channel with longitudinal vortex generators by applying field synergy principle analysis," International Communications in Heat and Mass Transfer, vol. 36, no. 2, pp. 111-120, 2009.

[15] L. Tian, Y. He, Y. Tao, and W. Tao, "A comparative study on the air-side performance of wavy fin-and-tube heat exchanger with punched delta winglets in staggered and in-line arrangements," International Journal of Thermal Sciences, vol. 48, no. 9, pp. 1765-1776, 2009.

[16] FLUENT Incorporated, FLUENT 6.3 User's Guide, Fluent Incorporated, Lebanon, NH, USA, 2006.

[17] H. Y. Li, C. L. Chen, S. M. Chao, and G. F. Liang, "Enhancing heat transfer in a plate-fin heat sink using delta winglet vortex generators," International Journal of Heat and Mass Transfer, vol. 67, pp. 666-677, 2003.

[18] C. L. Chen, Heat transfer enhancement of plate-fin heat sink by delta winglet vortex generators [M.S. thesis], Huafan University, New Taipei, Taiwan, 2012. 


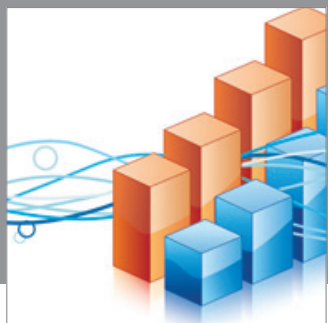

Advances in

Operations Research

mansans

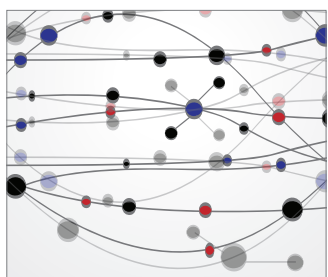

The Scientific World Journal
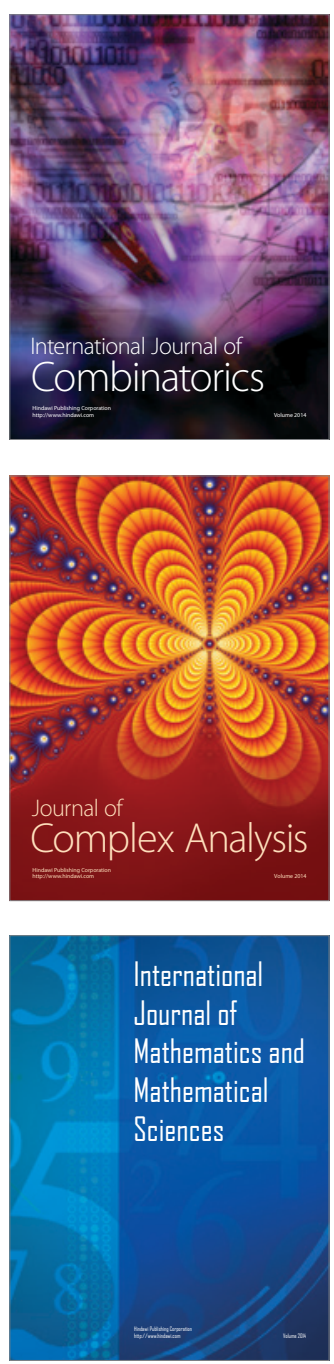
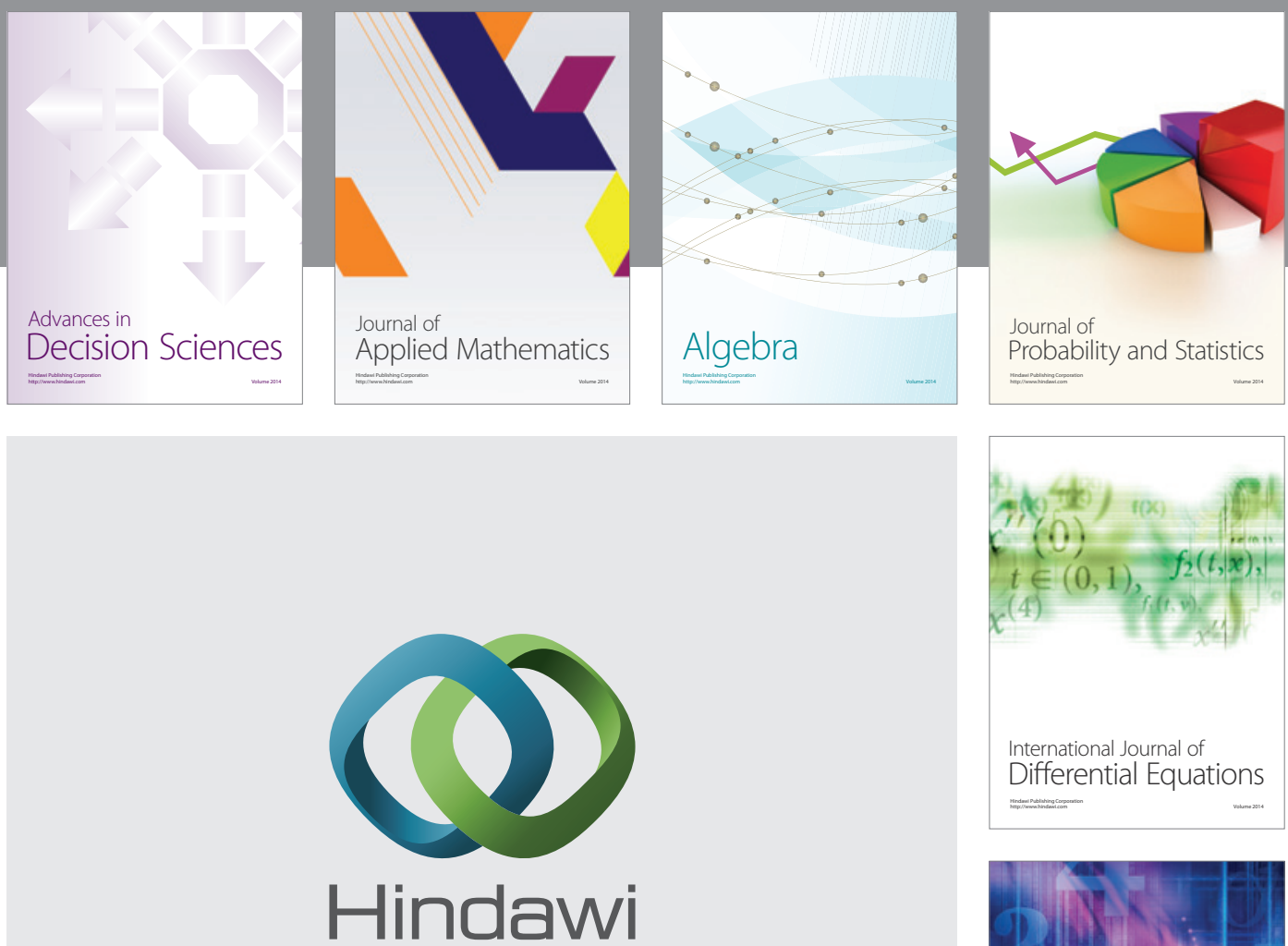

Submit your manuscripts at http://www.hindawi.com
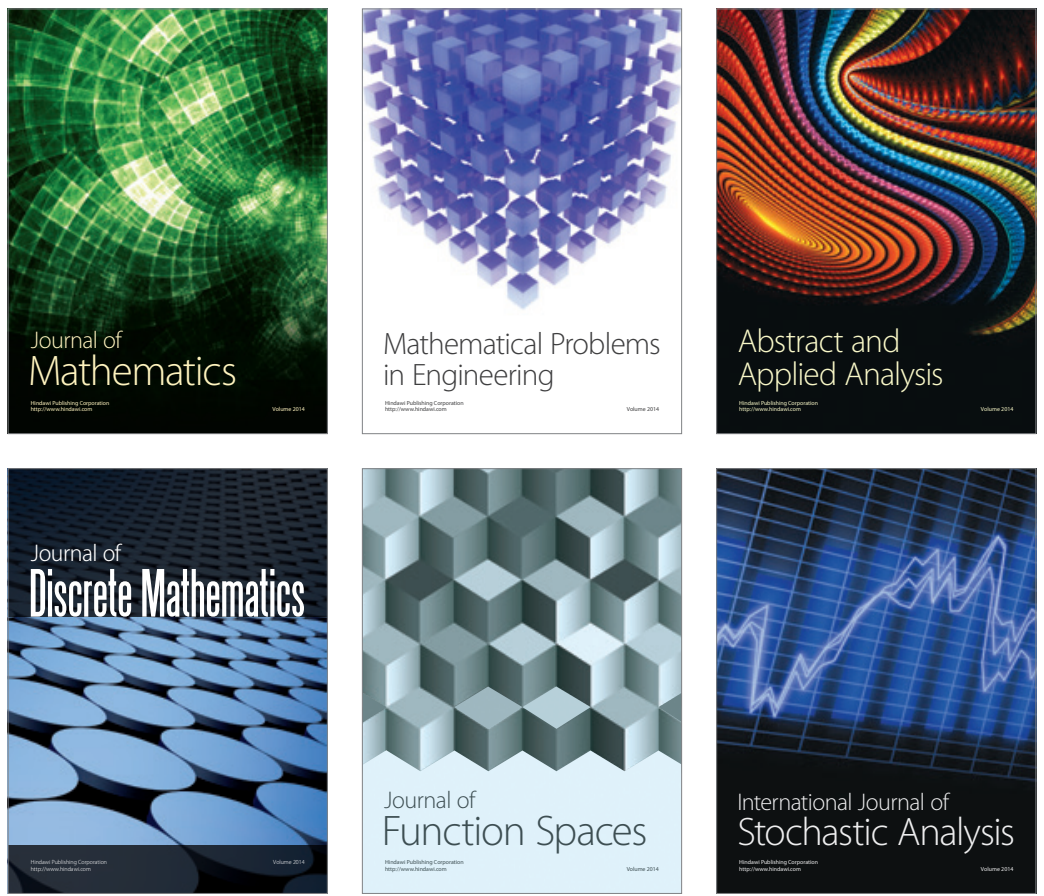

Journal of

Function Spaces

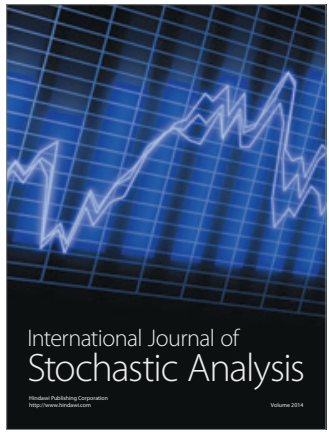

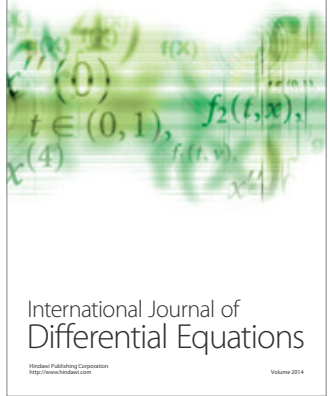
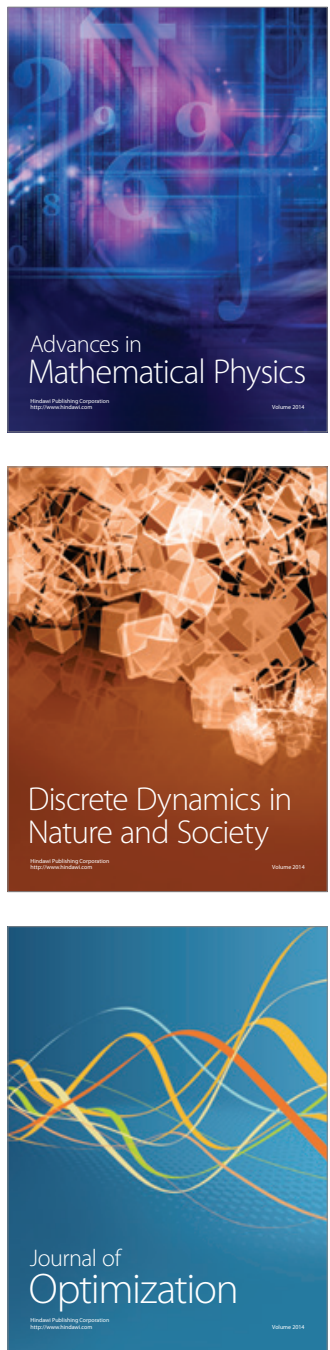